Kansas State University Libraries

New Prairie Press

\title{
ALTERNATIVE ESTIMATION TECHNIQUES FOR ASSESSING PROBABILITY OF FROST DAMAGE IN SUBALPINE FIR TREES
}

William J. Price

Bahman Shafii

Danny L. Barney

Follow this and additional works at: https://newprairiepress.org/agstatconference

Part of the Agriculture Commons, and the Applied Statistics Commons

\section{c) (1) $\Theta$}

This work is licensed under a Creative Commons Attribution-Noncommercial-No Derivative Works 4.0 License.

\section{Recommended Citation}

Price, William J.; Shafii, Bahman; and Barney, Danny L. (2007). "ALTERNATIVE ESTIMATION TECHNIQUES FOR ASSESSING PROBABILITY OF FROST DAMAGE IN SUBALPINE FIR TREES," Conference on Applied Statistics in Agriculture. https://doi.org/10.4148/2475-7772.1106

This is brought to you for free and open access by the Conferences at New Prairie Press. It has been accepted for inclusion in Conference on Applied Statistics in Agriculture by an authorized administrator of New Prairie Press. For more information, please contact cads@k-state.edu. 


\title{
ALTERNATIVE ESTIMATION TECHNIQUES FOR ASSESSING PROBABILITY OF FROST DAMAGE IN SUBALPINE FIR TREES
}

\author{
William J. Price ${ }^{1}$, Bahman Shafii ${ }^{1,2}$, and Danny L. Barney ${ }^{2}$ \\ ${ }^{1}$ Statistical Programs \\ ${ }^{2}$ Department of Plant, Soil, and Entomological Sciences \\ College of Agricultural and Life Sciences \\ University of Idaho, Moscow, ID
}

\begin{abstract}
Subalpine fir (Abies lasiocarpa var. lasiocarpa) is commonly used for nursery stock and Christmas tree applications. Spring frost damage to new buds, however, can jeopardize the longterm investment of growers and reduce the quality of the resulting fir trees. Hence, it is important to evaluate the risk of frost damage when considering prospective growing sites. A prediction model for bud development based on heat units can be used in conjunction with historical climate data to assess the likelihood of frost damage. That is, given the probability of a frost event at a given location and time, and the corresponding probability of bud break at that time, the probability of frost damage can be estimated. Factors affecting estimation, such as multiple environments inherent in the data, as well as temporal variation, must also be considered. These issues will be explored using parametric, non-parametric, and computer intensive estimation techniques. Examples will be demonstrated using data collected from replicated bud break experiments conducted in northern Idaho.
\end{abstract}

\section{Introduction}

Subalpine fir (Abies lasiocarpa var. lasiocarpa) is widely distributed from Arizona and New Mexico north in the Rocky mountains, Cascade Mountains, and eastern slopes of the Oregon and Washington Coast Mountains to the Yukon Territory in Canada and along the Pacific Coast in southeastern Alaska (Alexander et al., 1990). Economically, this species can be useful for landscape or nursery stock, and is suited for Christmas tree production. For landscape/nursery production, long growing cycles of up to 12 years may be necessary, as larger trees lead to higher profit margins for the producers. While Christmas tree production requires less time, crop cycles may still take from 7 to 10 years. During this time, it is important that the trees maintain a symmetric and appealing conical shape. Although producers can prune and trim the trees to achieve a desired form, environmental influences such as frost damage can alter the growth pattern of the trees and lead to decreased crop quality or even crop loss. During the growing season, the trees are most vulnerable to damaging frost events early in the spring when new bud growth is initiating (bud break). Hence, it is important to evaluate potential production sites for the risk of frost damage at these times, prior to planting the crop.

This paper seeks to develop a heat unit based probability model for estimating bud break in subalpine fir. The model is then combined with historical climate data related to time of last 
frost to produce a frost damage risk assessment for subalpine fir. The process of model development and application will be demonstrated using subalpine fir bud break data collected from Northern Idaho.

\section{Data}

\section{Methods}

Ten national forest sites in the southwest United States were selected for subalpine fir seed collection (Barney, 2005). From the initial seed collections, 60 seedlings per seed collection site were grown out and transplanted to a field at the University of Idaho Sandpoint Research \& Extension Center in Sandpoint, Idaho. The transplants were set out in a randomized complete block design with three blocks, each containing 20 seedlings from each seed collection site. In early spring, 15 randomly selected trees from each of the ten seed sources were examined for bud break approximately every other day. A tree was considered to have broken bud if at least one bud on the tree had opened. Measurements continued until all trees had broken bud. For trees which did not survive the winter seasons, measurements were provided by using the next available tree in the field plots. Data on bud break were collected for the years 2002 through 2006.

\section{Bud Break}

In order to model the process of bud break over multiple years, thermal heat units, hu, were used as a standardized temporal measurement. Heat units in this case were defined as:

$$
h u=\left(T_{\text {MAX }}+T_{\text {MIN }}\right) / 2-\text { Base }
$$

where $T_{\text {MAX }}$ and $T_{\text {MIN }}$ are the daily maximum and minimum temperatures, respectively, and Base is a base line temperature below which no growth occurs and no heat units are accumulated. For subalpine fir, a base temperature of $40^{\circ} \mathrm{F}$ was assumed. Daily heat unit values were subsequently accumulated over time, $\mathrm{Hu}$, for use in the modeling process described below.

The probability of bud break given a fixed accumulation of heat units, $\mathrm{P}(\mathrm{B} \mid \mathrm{Hu})$, can be described as an increasing sigmoidal function. The logistic model provides a good approximation to such cumulative growth or development over time (see for example, Shafii and Price, 2001). This model can be described as:

$$
P(B \mid H u)=F(H u)=M\left[1+\exp \left(-K\left(H u-L_{50}\right)\right]^{-1}\right.
$$

where $P(B \mid H u)=F(H u)$ is the cumulative probability of bud break, $B$, given $\mathrm{Hu}$ heat units and $\mathrm{M}, \mathrm{K}$, and $\mathrm{L}_{50}$ are parameters representing the upper asymptote, rate and the number of heat units to $50 \%$ of maximum, respectively. For the data at hand, all trees eventually reached $100 \%$ bud break, hence, the upper asymptote, $\mathrm{M}$, was assumed to be 1.0.

Specific percentiles of this function, i.e. the heat units required to reach $\mathrm{Q} \%$ bud break, can then be determined as $\mathrm{H}_{\mathrm{Q}}=\mathrm{F}^{-1}(\mathrm{Q})$ and the corresponding probability of at least $\mathrm{Q} \%$ bud break by $H_{Q}$ heat units as $p\left(B_{Q} \mid H_{Q}\right)=1-F\left(H_{Q}\right)$.

For comparative purposes, $\mathrm{Eq}(2)$ was estimated by three methods: fixed nonlinear estimation, mixed nonlinear estimation, and nonparametric bootstrap estimation. These methods 
are outlined below.

The fixed nonlinear model assumes the general form:

$$
y_{i}=f(X \mid \beta)+e_{i}
$$

where $y_{i}$ is the response (bud break proportion) of the $i^{\text {th }}$ observation, $X$ is a vector of regressors (heat units), $\beta$ is the vector of unknown parameters from $\mathrm{Eq}(2)$, and $\mathrm{e}_{\mathrm{i}}$ are independent, identically distributed random error terms (Littell, et al., 2006). Estimation of Eq(3) can be carried out using the maximum likelihood technique with the binomial likelihood given by:

$$
L\left(\Pi_{i}\right) \propto \prod\left(\Pi_{i}\right)^{y_{i}}\left(1-\Pi_{i}\right)^{N-y_{i}}
$$

where $\pi_{\mathrm{i}}$ is the logistic function given in $\mathrm{Eq}(2), \mathrm{N}$ is the total number of observations, and $\mathrm{y}_{\mathrm{i}}$ is as defined above.

The general form of the mixed nonlinear model :

$$
y_{i}=f(X \mid \beta, \theta)+\varepsilon_{i}
$$

is similar to that of the fixed model, $\mathrm{Eq}(3)$, with the addition of a vector of random parameter effects, $\theta . \varepsilon_{\mathrm{i}}$ is again assumed to be a vector of independent and randomly distributed errors (see for example Littell, et al., 2006). The binomial likelihood form from Eq(4) is similarly modified using a marginal likelihood (SAS, 2004) given by:

$$
m\left(\Pi_{i}\right) \propto \prod_{i=1}^{N} \int_{\theta}\left(\Pi_{i}\right)^{y_{i}}\left(1-\Pi_{i}\right)^{N-y_{i}} \cdot g(\theta) \delta_{\theta}
$$

where $g(\theta)$ is the distribution of the random vector, $\theta$, assumed to be $\mathrm{N}\left(0, \sigma^{2}\right)$.

The iterative bootstrap estimation technique was based on the fixed nonlinear form and can be generalized as:

$$
y_{i}^{*}=f(X \mid \beta)+e_{i}
$$

where $X, \beta$, and $e_{i}$ are as defined above and $y_{i}^{*}$ is a random sample of the data $y_{i}$ (Efron and Tibshirani, 1993). The bootstrap algorithm proceeded by 1) taking a random sample, $\mathrm{y}_{\mathrm{i}}$, of size $\mathrm{N}$ from the data $\mathrm{y}_{\mathrm{i}}$,2) maximizing the likelihood in $\mathrm{Eq}(4)$ and recording the estimated parameter vector, $\hat{\beta}$. Steps 1 and 2 were then repeated $B$ times where $B$ is a large number of bootstrap iterations. The results of the B iterations were then used to develop empirical bootstrap distributions for the parameters in $\beta$.

\section{Frost times}

The probability of a frost event at a specified location was based on historical weather data. The state of Idaho has historical weather data available at numerous locations, some recording up to 100 years of data. Hence, for a site of interest, the corresponding historical weather records were used to develop an empirical distribution of the number of heat units before the last frost event. As with bud break, this distribution was then used to determine the probability of a frost event at or exceeding $\mathrm{H}_{\mathrm{U}}$ heat units, $\mathrm{p}\left(\mathrm{Fr} \mid \mathrm{H}_{\mathrm{U}}\right.$, $)$. 


\section{Frost Damage}

Given the probabilities of bud break and frost time above, and assuming the events of bud break and frost time are independent, the probability of frost damage, $p\left(D \mid H_{U}\right)$ was computed as the product:

$$
p\left(D \mid H_{U}\right)=p\left(B \mid H_{U}\right) \cdot p\left(F r \mid H_{U}\right)
$$

Using Eq(8), a range of frost damage probabilities were then computed assuming various percentages, Q, of the potential bud break.

All statistical computations and graphics were carried out using SAS 9.1.

\section{Empirical Results}

As part of the bud break estimation process, Eq(2) was estimated separately for each year (2002-2006). In all cases, the estimated models fit well and resulted in significant parameter estimates. While comparison of these fits is important to the estimation process, presentation of those results are not given here as the effects due to year to year variability on the estimations are encompassed in the results to follow and the objective of this study was to provide a single estimation of bud break over the entire set of available data.

\section{Fixed Nonlinear Bud Break Estimation}

Parameter estimates along with the $10^{\text {th }}, 50^{\text {th }}$, and $90^{\text {th }}$ percentile estimates for the fixed model estimation of $\mathrm{Eq}(2)$ are given in Table 1 . The estimated rate parameter, $\mathrm{K}$, is approximately 0.05 and the number of heat units necessary to reach $50 \%$ bud break, $\mathrm{L}_{50}$, is estimated at 172 . While both estimates are significantly different from zero, their corresponding standard errors are quite small. For example, the standard error of the $\mathrm{L}_{50}$ estimate is 0.5 or less than one calender day. This can also be seen in Figure 1 where the fitted model follows the data pattern well, while the $95 \%$ confidence bounds tightly surround the estimated curve. The tight precision is not realistic, however, given large sample size and the evident variability observed in the data.

\section{Mixed Model Bud Break Estimation}

Re-examination of the data shows that one source of variability in the data may be annual fluctuations (Figure 2). Such annual variations demonstrate that, despite the use of accumulated heat units, other environmental factors, such as over wintering conditions or the speed with which heat units are accumulated prior to bud break, are important. Because the source of this variation is unknown, the estimation process was augmented to account for annual effects. The mixed nonlinear model given in $\mathrm{Eq}(5)$ was used to this end, by allowing both the rate parameter, $\mathrm{k}$, and the lag parameter, $\mathrm{L}_{50}$, to have random components as well as a mutual covariance. Initial model evaluation, however, indicated that annual variation associated with the rate parameter, $\mathrm{K}$, was not significant, and, hence, it, and the corresponding covariance were not included in the final model (data not shown). Estimates for the final model, containing both fixed and random effects for the lag parameter are given in Table 1. As with the fixed nonlinear case, all parameter estimates and percentiles were significant. The mixed model, however, provided more reliable estimates of variability with the time to $50 \%$ bud break estimated at 169 heat units with a 
standard error of 7.7 heat units (approximately 1 - 2 calendar days). The fitted model and the corresponding 95\% confidence limits are shown in Figure 3. While the 95\% bounds do not capture all the variability, they do provide a more realistic approximation relative to the fixed nonlinear model estimation.

\section{Bootstrap Bud Break Estimation}

The final estimation technique used was the nonparametric bootstrap. This method can account for the observed annual variation without explicitly estimating random components. In order to achieve this, the bootstrap process was designed as a two phase process which reflected both the data structure and the experimental design. The initial phase randomly selected, with replacement, 5 of the available years (2002-2006). In the second phase, data was selected randomly with replacement from each of these years. This second step was carried out in a manner which preserved the three block RCB design and maintained sample sizes equivalent to those of the original data. Following data selection, the bootstrap sample was subjected to the fixed model estimation in $\operatorname{Eq}(3)$ and the final estimates as well as the $10^{\text {th }}, 50^{\text {th }}$, and $90^{\text {th }}$ percentiles were recorded. This two phased approach was repeated $\mathrm{B}=3600$ times, after which, the empirical bootstrap distributions for the parameter estimates and the percentiles were developed. The resulting bootstrap estimates and fitted curve are shown in Table 1 and Figure 4, respectively. The estimated values were essentially identical to those of the mixed nonlinear model estimation, while the standard errors were somewhat larger, especially in the case of the rate parameter, K. Given the similarity of the estimates and the relative complexity of the bootstrap process, the mixed model technique was selected as the appropriate method for bud break estimation.

\section{Bud Break Probability}

Table 2 presents the $10^{\text {th }}, 50^{\text {th }}$, and $90^{\text {th }}$ percentile estimates from the mixed nonlinear model estimation. As a conservative estimate of the heat units required for at least Q\% bud break, 95\% lower confidence bounds were computed for each percentile. Based on these lower limits, the probabilities of $\mathrm{Q} \%$ bud break given $\mathrm{H}_{\mathrm{Q}}$ or more heat units were determined and are also given in Table 2. As would be expected, the lower percentages of bud break correspond to higher probabilities. That is, for a fixed point in time early in the season, it is more likely to have a few, rather than most, buds open.

\section{Frost Event Probabilities}

Six locations across Idaho were selected to assess the potential for frost damage to subalpine fir trees. These sites were chosen to reflect a range of latitudes, elevations, and environmental conditions over the state of Idaho. The sites and respective elevations were: Boise (865 m), Bonners Ferry (563 m), Lewiston (438 m), Moscow (811 m), Pocatello (1353 m), and Sandpoint $(640 \mathrm{~m})$. The Lewiston and Pocatello sites provided the lowest and highest points, respectively, while the remaining sites represented intermediate elevations.

In order to assess the timing of last frost, it is necessary to define a biological frost event. Many plant species, including subalpine fir, can survive the nominal freezing point of $32^{\circ} \mathrm{F}$. Biological damage may not occur until lower temperatures are reached. For subalpine fir, $28^{\circ} \mathrm{F}$ 
was determined to be a likely temperature at which damage may occur. Damage, however, may also be dependent on the length of time spent at low temperatures. Data directly measuring this effect are not yet available in subalpine fir. Hence, freezing events in this study were evaluated over a range of temperatures $\left(27^{\circ} \mathrm{F}\right.$ to $\left.29^{\circ} \mathrm{F}\right)$ as a means of compensating for any cooling time effects.

Empirical distributions of last freeze times were then developed for each of the candidate freeze temperatures at each site. The probabilities of having a frost event on or exceeding the bud break times (Table 2) were computed for each of the specified distributions and are listed in Table 3. Generally within a site, the lower freezing temperature, $27^{\circ} \mathrm{F}$, and the later $90 \%$ bud break times gave lower probabilities of freezing. Across locations, the lowest site, Lewiston, provided smaller probabilities of freezing and the higher site, Pocatello, larger probabilities. As might be expected, geographic location and elevation are important factors influencing the time of the last frost.

\section{Frost Damage Probabilities}

Table 4 combines the previous results of bud break and frost probabilities using $\mathrm{Eq}(8)$. As was seen above, the lower freezing temperatures and higher bud break percentages lead to the lower probabilities of damage. Similarly, the lowest and highest altitude locations provide the lowest and highest probabilities, respectively. Figure 5 presents these probabilities in a graphical form. The freezing temperatures of $27^{\circ} \mathrm{F}$ and $28^{\circ} \mathrm{F}$ provide the best resolution between sites. Figure 5 also shows that some sites, such as Pocatello or Boise, have high probabilities for damage even at low bud break percentages, while locations like Lewiston have consistently lower probabilities of damage.

While the probabilities of damage presented above are informative, they only reflect the probability of freezing damage in any given year. Both the nursery and Christmas tree industries require multi-year cropping cycles. Figure 6 demonstrates the cumulative effect of the $28^{\circ} \mathrm{F}$ freezing temperature over a short period. The values shown are the probabilities of at least one damaging freeze in a five year period. As can be seen, this drastically increases the probability of damage at all locations and all percentages of bud break. Even the lowest elevation, Lewiston, has an approximately $50 \%$ chance of a damaging freeze when the trees are at $90 \%$ bud break. While seemingly extreme, these data are consistent with observations from the field experiments, where frost damage was recorded annually. These data do not, however, reflect the degree of damage or effects on tree quality. Further research will be required to adjust the damage estimates for these factors.

\section{Concluding Remarks}

The logistic growth model is an appropriate form for describing the probability of bud break in subalpine fir. When using standardized heat units as a proxy for calendar date, however, the model estimation process should account for variation among years using either a mixed nonlinear model or an iterative bootstrap technique.

While the biological point of freezing for subalpine fir is unknown, an approximation of $27^{\circ}$ to $28^{\circ} \mathrm{F}$ commonly accepted as adequate. More precise estimates for damage assessment, however, should account for both the temperature and the time spent at that temperature. Further 
experimentation in this area is planned by the authors. In addition, an assessment of the relationship between the degree of frost damage and subsequent tree quality should be determined. The evaluation of more sites across the state of Idaho as well as the direct incorporation of topographic characteristics such as elevation may also be used to improve frost damage assessments. These factors, along with the methods demonstrated in this paper, may then be used to generate a frost damage potential map of the state of Idaho for subalpine fir. Such a tool could prove valuable to potential growers considering an investment in subalpine fir nursery or Christmas tree stock.

\section{References}

Alexander, R.R., R.C. Shearer, and W.D. Shepperd. 1990. Abies lasiocarpa (Hook) Nutt.: Subalpine Fir. In: R.M. Burns and B.H. Honkala (Eds.) Silvics of North America: Volume 1. Conifers. Agriculture Handbook 654. U.S. Dept. Agr. For. Serv., Washington, DC.

Barney, D. L. 2005. Evaluation of corkbark and subalpine fir for their potential as ornamental nursery stock and Christmas trees - Grant No. NAC/ISDA 2005-3. Idaho State Department of Agriculture Nursery and Florists Advisory Committee 2004 Final Project Report.

Efron, B., and R. J. Tibshirani. 1993. An Introduction to the Bootstrap. Chapman Hall, NY.

Littell, R. C., G. A. Milliken, W. W. Stroup, R. D. Wolfinger, and O. Schabenberger. 2006. SAS for Mixed Models, Second Edition. SAS Institute Inc, Cary, NC.

SAS. 2004. SAS OnlineDoc ${ }^{\circledR}$ 9.1.3. Cary, NC: SAS Institute Inc.

Shafii, B. and W. J. Price. 2001. Estimation of cardinal temperatures in germination analysis. Journal of Agricultural, Biological, and Environmental Statistics. 6:3 pp 356-366. 
Table 1. Parameter estimates, standard errors, and p-values for logistic bud break model fir with three estimation methods. Estimates of the $10^{\text {th }}, 50^{\text {th }}$ and $90^{\text {th }}$ percentiles are also shown.

\section{Fixed Nonlinear Model}

\begin{tabular}{|c|r|r|c|}
\hline Parameter & Estimate & Std Err & $\mathbf{P}>\mathbf{t}$ \\
\hline K & 0.04961 & 0.0006 & 0.0001 \\
\hline L50 & 171.97 & 0.5059 & 0.0001 \\
\hline
\end{tabular}

\begin{tabular}{|l|l|l|l|}
\hline 10th & 127.68 & 0.6718 & 0.0001 \\
\hline 50th & 171.97 & 0.5059 & 0.0001 \\
\hline 90th & 216.27 & 0.7848 & 0.0001 \\
\hline
\end{tabular}

Mixed Nonlinear Model

\begin{tabular}{|c|r|r|c|}
\hline Parameter & Estimate & Std Err & P >t \\
\hline K & $\mathbf{0 . 0 8 7 1 6}$ & 0.0014 & 0.0001 \\
\hline L50 & 169.18 & 7.7174 & 0.0001 \\
\hline Var L50 & 29.8545 & 5.462 & 0.0001 \\
\hline
\end{tabular}

\begin{tabular}{|l|l|l|l|}
\hline 10th & 143.97 & 7.7259 & 0.0001 \\
\hline 50th & 169.18 & 7.7174 & 0.0001 \\
\hline 90th & 194.39 & 7.7294 & 0.0001 \\
\hline
\end{tabular}

\section{Bootstrap Model}

\begin{tabular}{|c|r|r|}
\hline Parameter & Estimate & Std Err \\
\hline K & 0.09 & 0.0110 \\
\hline L50 & 169.12 & 9.7890 \\
\hline
\end{tabular}

\begin{tabular}{|l|r|r|}
\hline 10th & 144.07 & 10.8828 \\
\hline 50th & 169.12 & 9.7890 \\
\hline 90th & 194.17 & 9.5521 \\
\hline
\end{tabular}


Table 2. The $10^{\text {th }}, 50^{\text {th }}$, and $90^{\text {th }}$ percentiles for bud break (heat units, $\mathrm{H}_{\mathrm{Q}}$ ) and the corresponding 95\% lower confidence bounds on each from the nonlinear mixed model estimation. Probability values, $\mathrm{P}\left(\mathrm{B} \mid \mathrm{H}_{\mathrm{Q}}\right)$, represent the probability of subalpine bud break at or beyond the lower bound.

\begin{tabular}{|l|l|r|r|}
\hline Percentile & $\mathrm{H}_{\mathrm{Q}}$ & $95 \%$ L. Bound & $\mathrm{p}\left(\mathrm{B} \mid \mathrm{HQ}_{\mathrm{Q}}\right)$ \\
\hline 10th & 144.0 & 130.4 & 0.975 \\
\hline 50th & 169.8 & 155.6 & 0.817 \\
\hline 90th & 194.4 & 180.8 & 0.335 \\
\hline
\end{tabular}

Table 3. Estimated probability of a frost event given $\mathrm{H}_{\mathrm{Q}}$ heat units, $\mathrm{P}\left(\mathrm{Fr} \mid \mathrm{H}_{\mathrm{Q}}\right)$, at three subalpine fir bud break percentiles $\left(10^{\text {th }}, 50^{\text {th }}, \& 90^{\text {th }}\right)$, for three frost cut-off temperatures $\left(27,28, \& 29^{\circ} \mathrm{F}\right)$ at six Idaho locations. The locations and number of available years for climate data of each were: Boise (70), Bonners Ferry (81), Lewiston (61), Moscow (87), Pocatello (68), and Sandpoint (97).

\begin{tabular}{|l|c|c|c|}
\multicolumn{4}{c|}{ Boise } \\
\hline & \multicolumn{3}{|c|}{$\mathrm{p}(\mathrm{Fr} \mid \mathrm{HQ})$} \\
\hline Percentile & $27^{\star} \mathrm{F}$ & $28^{*} \mathrm{~F}$ & $29^{\star} \mathrm{F}$ \\
\hline 10th & $\mathbf{0 . 7 8 2 6}$ & $\mathbf{0 . 9 1 3 0}$ & $\mathbf{0 . 9 5 6 5}$ \\
\hline 50th & $\mathbf{0 . 6 9 5 7}$ & $\mathbf{0 . 8 5 5 1}$ & $\mathbf{0 . 9 2 7 5}$ \\
\hline 90th & $\mathbf{0 . 6 0 8 7}$ & $\mathbf{0 . 8 1 1 6}$ & $\mathbf{0 . 8 8 4 1}$ \\
\hline
\end{tabular}

\begin{tabular}{|l|c|c|c|}
\multicolumn{4}{|c|}{ Lewiston } \\
\hline & \multicolumn{3}{|c|}{$\mathrm{p}(\mathrm{Fr} \mid \mathrm{HQ})$} \\
\hline Percentile & $27^{\star} \mathrm{F}$ & $28^{\star} \mathrm{F}$ & $29^{\star} \mathrm{F}$ \\
\hline 10th & $\mathbf{0 . 3 7 7 4}$ & $\mathbf{0 . 4 8 2 1}$ & $\mathbf{0 . 6 4 4 1}$ \\
\hline 50th & $\mathbf{0 . 3 3 9 6}$ & $\mathbf{0 . 4 4 6 4}$ & $\mathbf{0 . 5 7 6 3}$ \\
\hline 90th & $\mathbf{0 . 3 0 1 9}$ & $\mathbf{0 . 3 5 7 1}$ & $\mathbf{0 . 4 9 1 5}$ \\
\hline
\end{tabular}

\begin{tabular}{|l|c|c|c|}
\multicolumn{4}{|c|}{ Pocatello } \\
\hline & \multicolumn{3}{|c|}{$\mathrm{p}(\mathrm{Fr} \mid \mathrm{HQ})$} \\
\hline Percentile & $27^{*} \mathrm{~F}$ & $28^{*} \mathrm{~F}$ & $29^{*} \mathrm{~F}$ \\
\hline 10th & 0.7910 & 0.8806 & 0.8955 \\
\hline 50th & $\mathbf{0 . 6 4 1 8}$ & $\mathbf{0 . 7 6 1 2}$ & $\mathbf{0 . 7 9 1 0}$ \\
\hline 90th & 0.5821 & 0.6716 & 0.7015 \\
\hline
\end{tabular}

\begin{tabular}{|l|c|c|c|}
\multicolumn{4}{c|}{ Bonners Ferry } \\
\hline & \multicolumn{3}{|c|}{$\mathrm{p}(\mathrm{Fr} / \mathrm{HQ})$} \\
\hline Percentile & $27^{*} \mathrm{~F}$ & $28^{*} \mathrm{~F}$ & $29^{*} \mathrm{~F}$ \\
\hline 10th & 0.5513 & 0.6795 & 0.8333 \\
\hline 50th & 0.3846 & 0.6026 & 0.7308 \\
\hline 90th & 0.3333 & 0.5385 & 0.6795 \\
\hline
\end{tabular}

\begin{tabular}{|l|c|c|c|}
\multicolumn{4}{c|}{ Moscow } \\
\hline & \multicolumn{3}{|c|}{$\mathrm{p}(\mathrm{Fr} \mid \mathrm{HQ})$} \\
\hline Percentile & $27^{*} \mathrm{~F}$ & $28^{*} \mathrm{~F}$ & $29^{*} \mathrm{~F}$ \\
\hline 10th & 0.4483 & $\mathbf{0 . 6 3 2 2}$ & $\mathbf{0 . 7 8 1 6}$ \\
\hline 50th & 0.3908 & 0.5747 & 0.7471 \\
\hline 90th & 0.3103 & 0.4713 & 0.6552 \\
\hline
\end{tabular}

\begin{tabular}{|l|c|c|c|}
\multicolumn{4}{c|}{ Sandpoint } \\
\hline & \multicolumn{3}{|c|}{$\mathrm{p}(\mathrm{Fr} \mid \mathrm{HQ})$} \\
\hline Percentile & $27^{*} \mathrm{~F}$ & $28^{*} \mathrm{~F}$ & $29^{*} \mathrm{~F}$ \\
\hline 10th & 0.5263 & 0.6421 & 0.7684 \\
\hline 50th & $\mathbf{0 . 4 8 4 2}$ & 0.6211 & 0.7263 \\
\hline 90th & 0.4632 & 0.5895 & 0.7053 \\
\hline
\end{tabular}


Table 4. Estimated probability of frost damage given $\mathrm{H}_{\mathrm{Q}}$ heat units, $\mathrm{P}\left(\mathrm{D} \mid \mathrm{H}_{\mathrm{Q}}\right)$, at three percentiles of subalpine bud break $\left(10^{\text {th }}, 50^{\text {th }}, \& 90^{\text {th }}\right)$, for three frost cut off temperatures $\left(27,28, \& 29^{\circ} \mathrm{F}\right)$, and at six Idaho locations.

\begin{tabular}{|l|c|c|c|}
\multicolumn{4}{c}{ Boise } \\
\hline & \multicolumn{3}{|c|}{$\mathrm{p}(\mathrm{D} / \mathrm{HQ})$} \\
\hline Percentile & $27^{*} \mathrm{~F}$ & $28^{*} \mathrm{~F}$ & $29^{*} \mathrm{~F}$ \\
\hline 10th & 0.7633 & 0.8905 & 0.9329 \\
\hline 50th & 0.5685 & 0.6988 & 0.7580 \\
\hline 90th & 0.2041 & 0.2721 & 0.2964 \\
\hline
\end{tabular}

\begin{tabular}{|l|c|c|c|}
\multicolumn{4}{c|}{ Bonners Ferry } \\
\hline & \multicolumn{3}{|c|}{$\mathrm{p}(\mathrm{D} \mid \mathrm{HQ})$} \\
\hline Percentile & $27^{*} \mathrm{~F}$ & $28^{*} \mathrm{~F}$ & $29^{*} \mathrm{~F}$ \\
\hline 10th & $\mathbf{0 . 5 3 7 7}$ & $\mathbf{0 . 6 6 2 7}$ & $\mathbf{0 . 8 1 2 8}$ \\
\hline 50th & $\mathbf{0 . 3 1 4 3}$ & $\mathbf{0 . 4 9 2 4}$ & $\mathbf{0 . 5 9 7 2}$ \\
\hline 90th & $\mathbf{0 . 1 1 1 8}$ & $\mathbf{0 . 1 8 0 6}$ & $\mathbf{0 . 2 2 7 8}$ \\
\hline
\end{tabular}

\begin{tabular}{|l|c|c|c|}
\multicolumn{4}{|c|}{ Lewiston } \\
\hline & \multicolumn{3}{|c|}{$\mathrm{p}(\mathrm{D} / \mathrm{HQ})$} \\
\hline Percentile & $27^{*} \mathrm{~F}$ & $28^{*} \mathrm{~F}$ & $29^{*} \mathrm{~F}$ \\
\hline 10th & 0.3680 & 0.4702 & 0.6282 \\
\hline 50th & $\mathbf{0 . 2 7 7 5}$ & 0.3648 & 0.4709 \\
\hline 90th & 0.1012 & 0.1198 & 0.1648 \\
\hline
\end{tabular}

\begin{tabular}{|l|c|c|c|}
\multicolumn{4}{c|}{ Moscow } \\
\hline & \multicolumn{3}{|c|}{$\mathrm{p}(\mathrm{D} \mid \mathrm{HQ})$} \\
\hline Percentile & $27^{\star} \mathrm{F}$ & $28^{*} \mathrm{~F}$ & $29^{\star} \mathrm{F}$ \\
\hline 10th & $\mathbf{0 . 4 3 7 2}$ & $\mathbf{0 . 6 1 6 6}$ & $\mathbf{0 . 7 6 2 3}$ \\
\hline 50th & $\mathbf{0 . 3 1 9 4}$ & $\mathbf{0 . 4 6 9 7}$ & $\mathbf{0 . 6 1 0 6}$ \\
\hline 90th & $\mathbf{0 . 1 0 4 1}$ & $\mathbf{0 . 1 5 8 0}$ & $\mathbf{0 . 2 1 9 7}$ \\
\hline
\end{tabular}

\begin{tabular}{|l|c|c|c|}
\multicolumn{4}{c|}{ Pocatello } \\
\hline & \multicolumn{3}{|c|}{ P( D / Ha) } \\
\hline Percentile & $27^{*} \mathrm{~F}$ & $28^{*} \mathrm{~F}$ & $29^{*} \mathrm{~F}$ \\
\hline 10th & 0.7715 & 0.8589 & 0.8734 \\
\hline 50th & 0.5245 & 0.6221 & 0.6464 \\
\hline 90th & 0.1952 & 0.2252 & 0.2352 \\
\hline
\end{tabular}

\begin{tabular}{|l|c|c|c|}
\multicolumn{4}{c|}{ Sandpoint } \\
\hline & \multicolumn{3}{|c|}{$\mathrm{p}(\mathrm{D} \mid \mathrm{HQ})$} \\
\hline Percentile & $27^{*} \mathrm{~F}$ & $28^{\star} \mathrm{F}$ & $29^{\star} \mathrm{F}$ \\
\hline 10th & 0.5133 & 0.6263 & 0.7494 \\
\hline 50th & 0.3957 & 0.5075 & 0.5936 \\
\hline 90th & 0.1553 & 0.1977 & 0.2365 \\
\hline
\end{tabular}




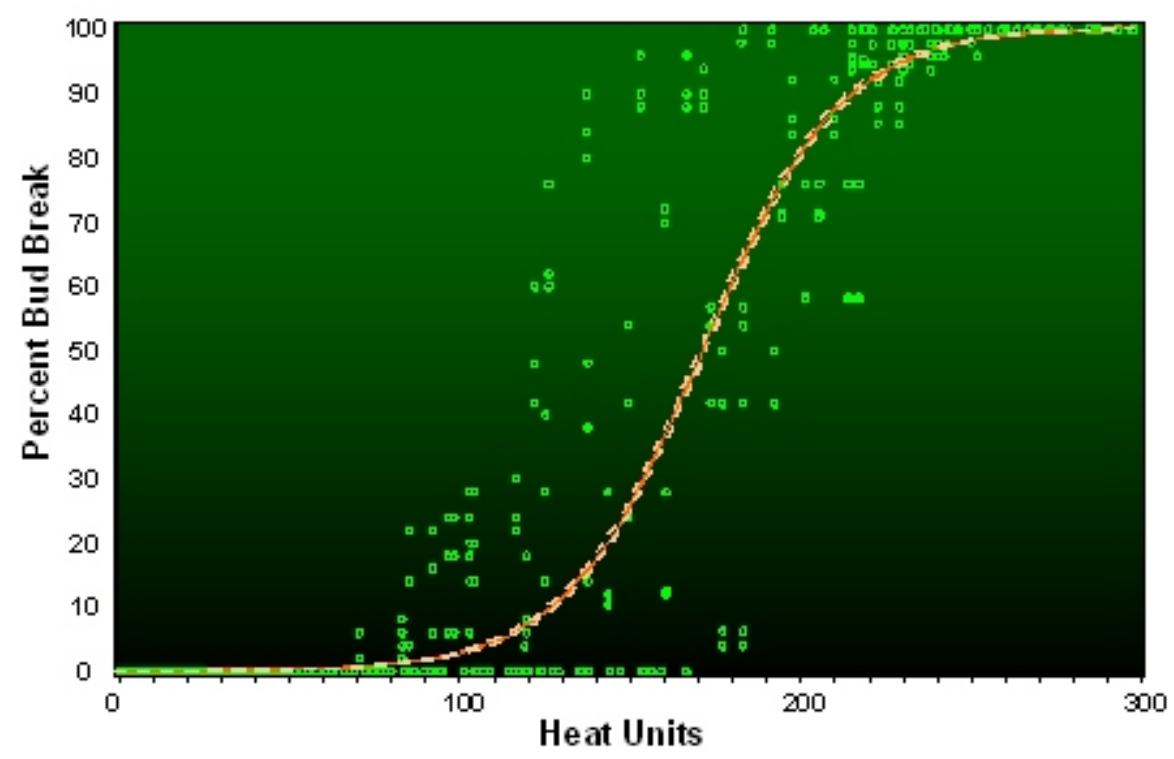

Figure 1. Fixed nonlinear fit of the logistic growth model to subalpine fir bud break data.

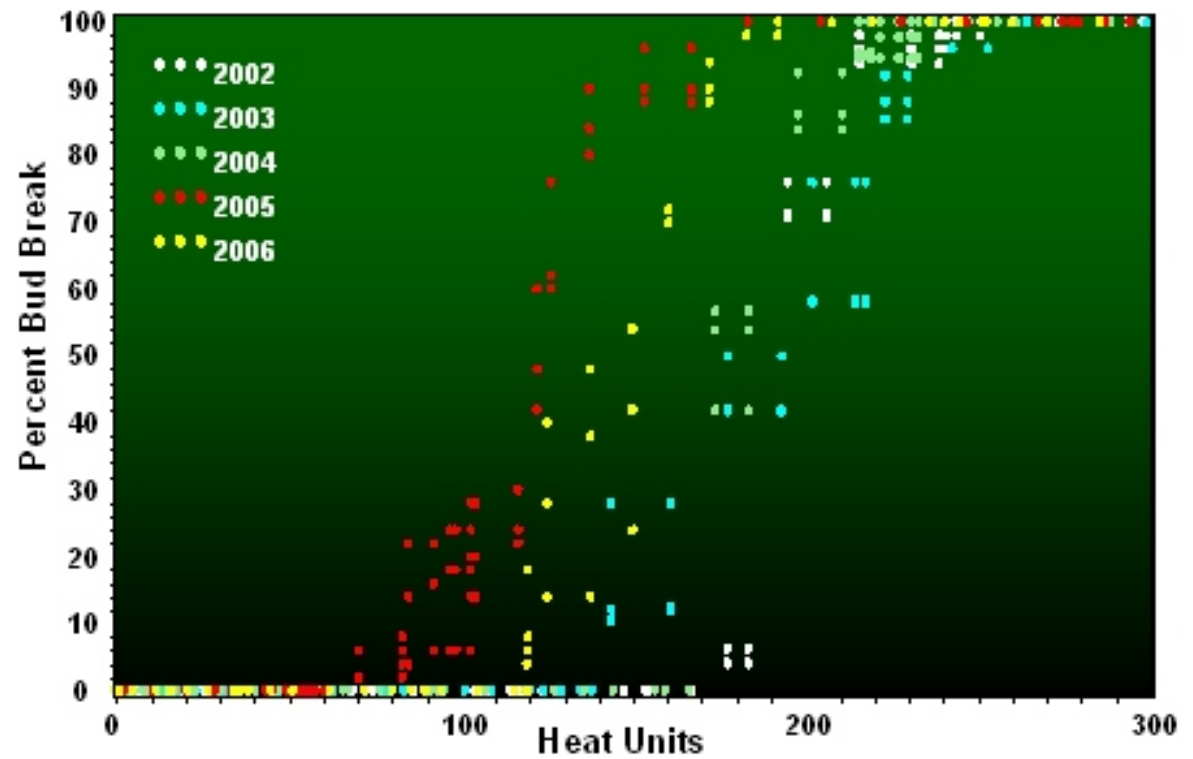

Figure 2. Subalpine fir bud break data displayed by year. 


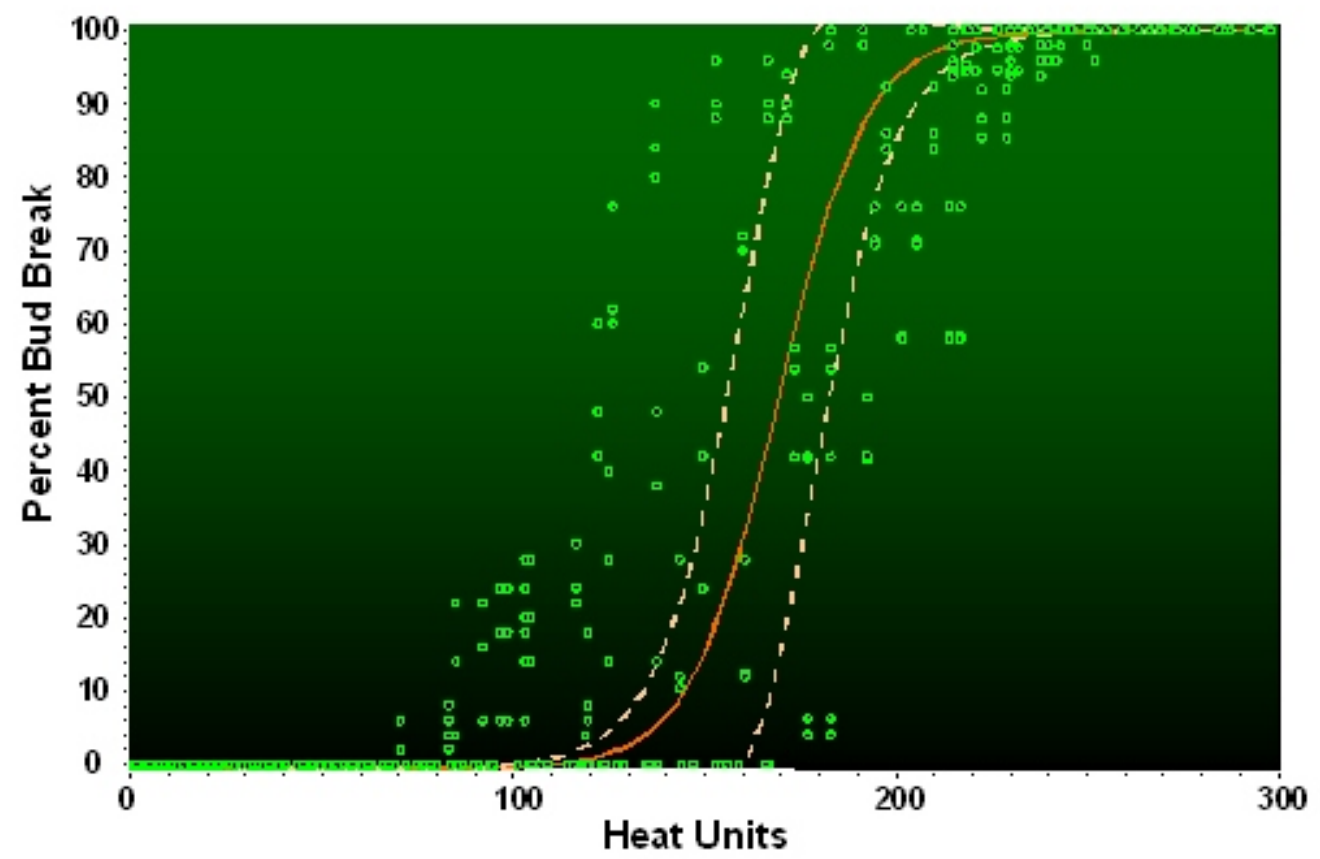

Figure 3. Mixed nonlinear fit of the logistic growth model to subalpine fir bud break data.

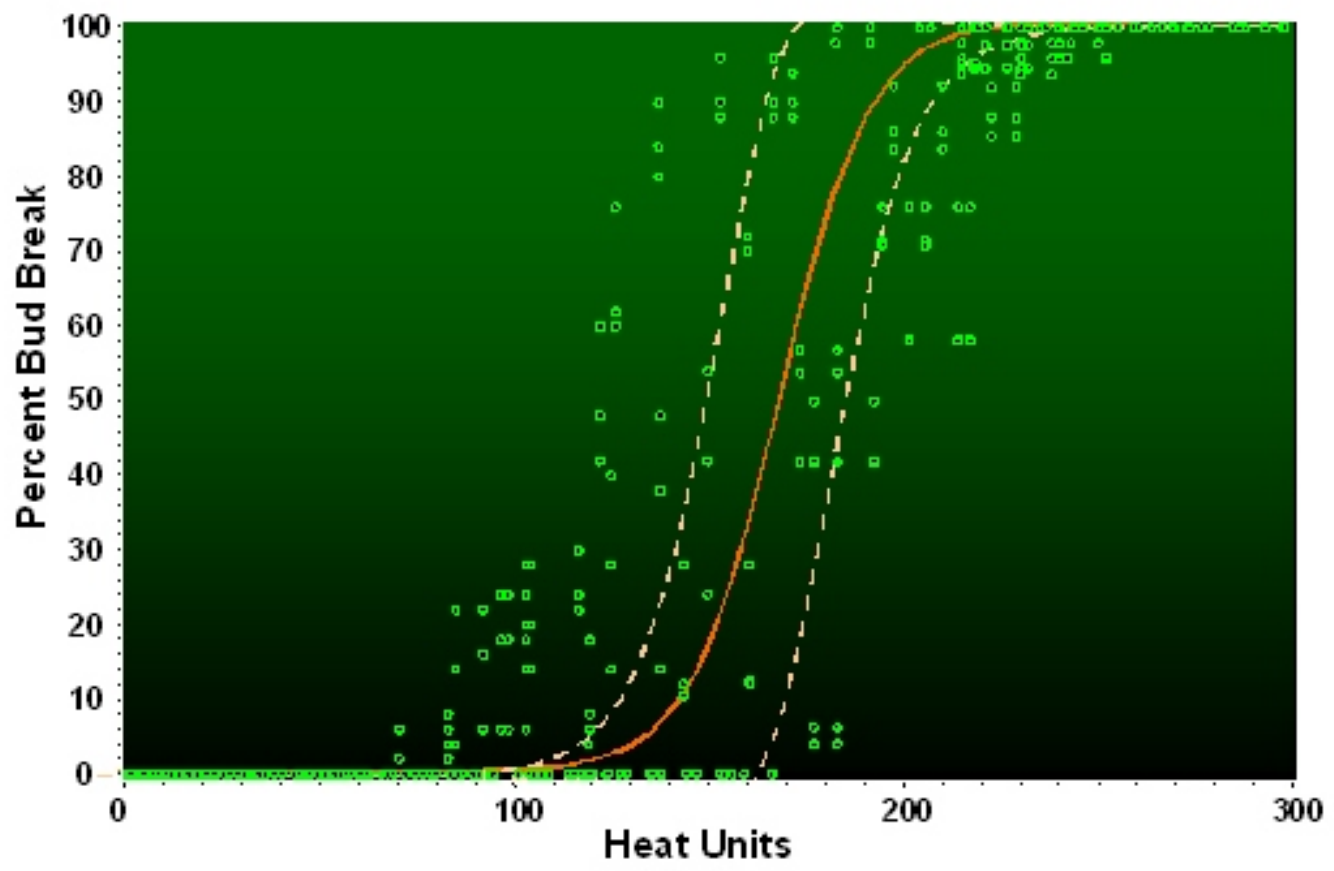

Figure 4. Bootstrap fit of the logistic growth model to subalpine fir bud break data. 


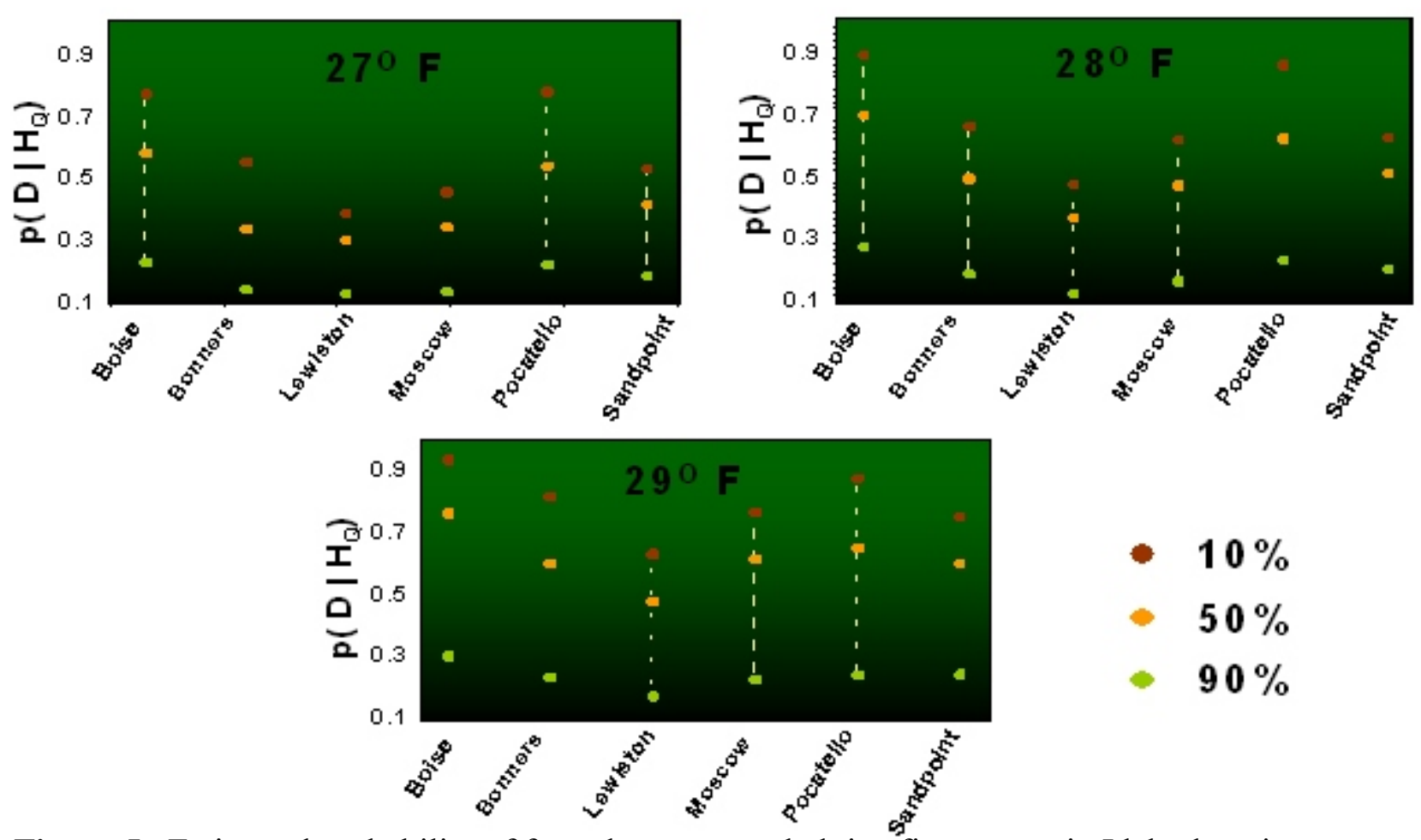

Figure 5. Estimated probability of frost damage to subalpine fir trees at six Idaho locations, three frost temperatures, and three levels of bud break.

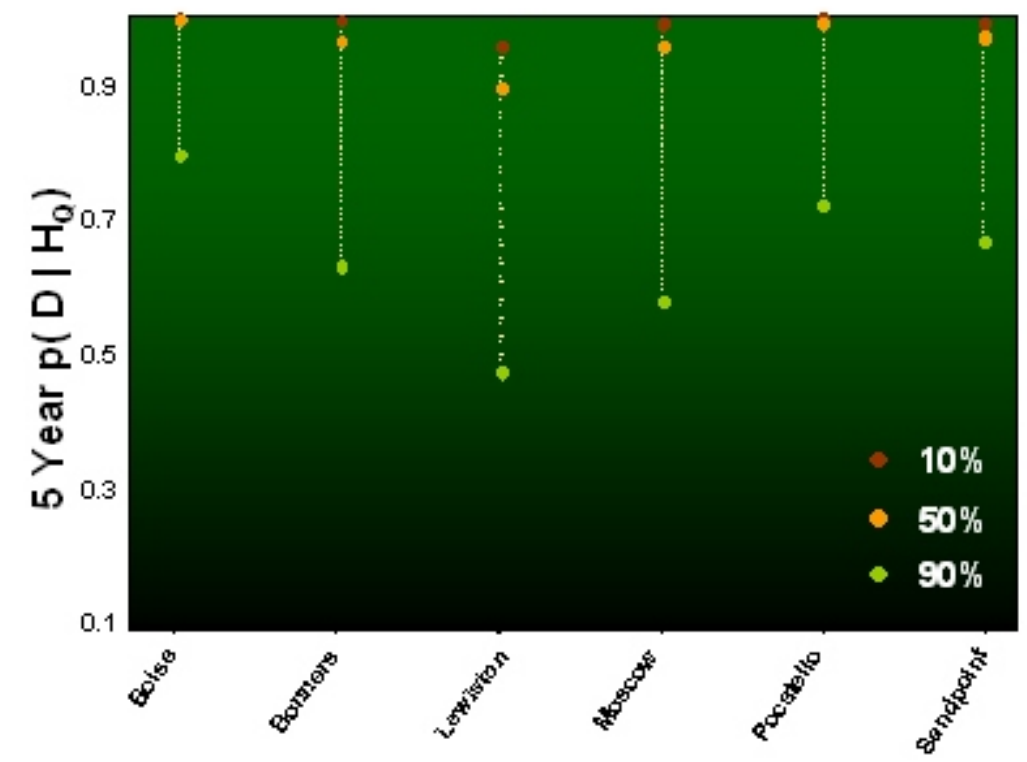

Figure 6. Estimated probability of frost damage to subalpine fir trees at six Idaho locations, three frost temperatures, and three levels of bud break over a five year period. 